\title{
DERECHO CONSTITUCIONAL AMBIENTAL BRASILEÑO A LA LUZ DE UNA POSMODERNIDAD
}

\author{
JosÉ RubENS MoRATO LEITE \\ Profesor asociado IV de los cursos de grado y posgrado en derecho de la Universidade \\ Federal de Santa Catarina (UFSC) \\ E-mail: morato.1@ufsc.br
}

\section{Germana Parente Neiva Belchior}

Doctoranda en derecho por Universidade Federal de Santa Catarina (UFSC)

E-mail: germana_belchior@yahoo.com.br

\author{
CARlos E. Peralta \\ Investigador del Grupo de investigación Direito Ambiental e Ecologia Política na \\ Sociedade de Risco (GPDA/UFSC) \\ E-mail: carlosperalta07@gmail.com
}

Recibido: 25 de febrero de 2014 / Aceptado: 19 de mayo de 2014

RESUMEN: A la luz de una sociedad posmoderna, compleja, de riesgos imprevisibles y ecológicamente inestable, las fuentes del derecho ambiental son cada vez más plurales y heterogéneas. En el presente caso de estudio, enmarcado dentro de la realidad del ordenamiento jurídico brasileño, la Constitución Federal de 1988 es el punto de partida de todo el procedimiento de interpretación y aplicación de las normas que protegen el medio ambiente. En este contexto, el objetivo de este artículo es presentar los aspectos más relevantes de la protección constitucional del medio ambiente en Brasil, al considerar esta disciplina como el eje lógico jurídico-ambiental brasileño y, por ende, la base del estudio del derecho ambiental. La legislación ambiental brasileña debe ser vista 
desde la perspectiva de la crisis ambiental, la posmodernidad y el concepto de sociedad de riesgo en la medida en que las mutaciones normativas constitucionales contribuyen a la adecuación de la legislación a la realidad y, por lo tanto, al desarrollo progresivo de la disciplina del derecho ambiental.

RESUM: A la llum d'una societat postmoderna, complexa, de riscos imprevisibles i ecològicament inestable, les fonts del dret ambiental són cada vegada més plurals i heterogènies, i dins del enmarcament del cas en estudi de la realitat del ordenament jurídic brasiler, la Constitució Federal de 1988 es el punt de partida de tot el procés d'interpretació i aplicació de les normes que tutelen el medi ambient. Amb aquest plantejament, l'objectiu d'aquest article és presentar els aspectes més rel-levants de la protecció constitucional del medi ambient, essència de la lògica juridicoambiental brasilera, i així, la base de l'estudi del dret ambiental. La legislació ambiental brasilera s'ha de llegir des de la perspectiva de la crisis ambiental, postmodernitat i del concepte de societat de risc, en la mesura que las mutacións normatives constitucionals contribueixen a l'adequació de la legislació a la realitat i, per tant, permeteix el desenvolupament progressiu de l'assignatura del dret ambiental.

ABSTRACT: In the context of a post-modern, complex and ecologically unstable society with unpredictable risks, the sources of environmental law are becoming increasingly pluralistic and heterogeneous. In this case study, framed within the reality of the Brazilian legal order, the Federal Constitution of 1988 is the starting point for the entire process of interpretation and application of environmental protection standards. In this context, the aim of this paper is to present the most relevant aspects of the constitutional protection of the environment in Brazil, considering this discipline as the Brazilian legal-environmental axis and, hence, the basis of the study of environmental law. Brazilian environmental legislation must be viewed from the perspective of the environmental crisis, postmodernism and the concept of risk society to the extent that constitutional rules mutations contribute to the adaptation of legislation to reality and, therefore, the progressive development of the discipline of environmental law. 
PALABRAS CLAVE: Derecho constitucional ambiental — Posmodernidad Derecho brasileño — Derechos fundamentales — Hermenéutica ambiental.

PARAULES CLAU: Dret constitucional ambiental — Postmodernitat — Dret brasiler — Drets fonamentals - Hermenèutica ambiental.

KEYWORDS: Environmental constitutional law — Post-modernity — Brazilian law — Fundamental rights — Environmental hermeneutics.

SUMARIO: I. Introducción. II. Discusión. 1. El medio ambiente ecológicamente equilibrado como derecho fundamental. 1.1. La naturaleza principiológica del derecho fundamental al medio ambiente ecológicamente equilibrado y su contenido esencial. 1.2. La doble dimensión del derecho fundamental al medio ambiente. 1.3. La titularidad del derecho fundamental al medio ambiente: la necesidad de un abordaje ético. 2. El medio ambiente ecológicamente equilibrado como deber fundamental. 3. El Estado de derecho ambiental. 4. Elementos de una hermenéutica jurídica ambiental. III. Conclusión. IV. Bibliografía

\section{INTRODUCCIÓN}

A la luz de una sociedad posmoderna, compleja, de riesgos imprevisibles y ecológicamente inestable, las fuentes del derecho ambiental son cada vez más plurales y heterogéneas, siendo la Constitución Federal el punto de partida de todo el proceso de interpretación y aplicación de las normas que tutelan el medio ambiente.

Dentro de ese contexto, la Constitución Federal de Brasil de 1988 asegura, de forma inédita en el país, que el medio ambiente ecológicamente equilibrado es un derecho y un deber fundamental, conforme a la redacción del artículo 225, matriz ecológica del ordenamiento jurídico brasileño que impone un conjunto de obligaciones positivas y negativas vinculadas a la tutela ambiental.

Son muchos los desafíos que deben ser afrontados por los iusambientalistas, motivo por el cual el estudio del Derecho constitucional ambiental es esencial para proporcionar al operador jurídico una lectura más dinámica y sistémica del fenómeno de la ecologización del Derecho.

El objetivo de este artículo es, por lo tanto, presentar los aspectos más relevantes de la protección constitucional del medio ambiente, cuyo foco será el análisis del artículo 
225, de donde irradian las demás normas ambientales brasileñas. Captar la esencia del citado dispositivo es comprender la lógica jurídico-ambiental brasileña, pues es la base del estudio del Derecho ambiental.

En la primera parte será abordado el medio ambiente ecológicamente equilibrado como derecho fundamental en el ordenamiento jurídico brasileño, conforme a lo previsto en el artículo 225 de la Carta Magna, a partir del análisis de su naturaleza jurídica, titularidad, contenido, dimensión, eficacia y restricciones. En atención al espíritu del consenso constitucional, serán analizados el medio ambiente en cuanto deber fundamental y las consecuencias del referido imperativo para el Estado, la sociedad y el ciudadano.

Posteriormente, serán discutidos los fundamentos del Estado de derecho ambiental, paradigma que viene siendo defendido en la doctrina como instrumento de protección del medio ambiente, a la luz de la posmodernidad y de la sociedad de riesgo. Por último, serán presentados los elementos de una hermenéutica jurídica ambiental con el objetivo de orientar y guiar al intérprete, con el objeto de captar el sentido del orden jurídico ambiental de acuerdo con los postulados del Estado de derecho ambiental.

Para darle un carácter pragmático al estudio, serán examinados, a lo largo del capítulo, resoluciones de las cortes superiores, en especial del Superior Tribunal de Justiça (STJ) de Brasil, dado que es exactamente por medio de decisiones judiciales que las normas jurídicas son retiradas del distante mundo del “deber-ser”, para utilizar la expresión de Kelsen, y llevadas a la realidad, al "ser", donde efectivamente se hacen valer por medio del análisis realizado por el intérprete que juzga.

\section{DISCUSIÓN}

\section{EI medio ambiente ecológicamente equilibrado como derecho fundamental}

El constituyente brasileño, inspirado en constituciones occidentales sociales democráticas del siglo anterior, estableció en el artículo $1 .^{\circ}$, inciso III, el postulado de la dignidad de la persona humana entre los fundamentos de la organización nacional. De hecho, puede afirmarse que el Estado democrático de la actualidad es un Estado de apertura constitucional radicado en el principio de la dignidad del ser humano, considerado su eje central. Se trata, así, de un constitucionalismo de las comunidades humanas, más orgánico y más dirigido a la sociedad que al Estado. 
Siendo el Estado democrático de derecho la fórmula política adoptada por el constituyente originario, de acuerdo con lo dispuesto en el artículo $1 .^{\circ}$, caput, de la Constitución Federal, GUERRA FILHO afirma que toda interpretación del texto constitucional debe ser realizada buscando conferirle el máximo de eficacia, presentándose como un programa de acción que deberá ser compartido por todos los integrantes de la comunidad política ${ }^{1}$.

Sin embargo, todavía perdura en el Estado contemporáneo lo esencial de la concepción liberal, que se traduce en la afirmación de que el hombre, por el simple hecho de serlo, tiene derechos y que el poder público debe respetarlos. Asegurar el respeto de la dignidad humana continúa siendo la finalidad de la sociedad política. Dignidad que, sin embargo, no es vista apenas en el ámbito del individuo aislado, pero sí de una forma colectiva en virtud de la solidaridad.

Por esa razón, surgen derechos de titularidad colectiva, clasificados por la doctrina como derechos fundamentales de tercera generación, frente a los derechos de primera generación, propios del Estado liberal, y los de segunda generación, surgidos en el marco del Estado social. Consagran el principio de la solidaridad, englobando, también, el medio ambiente ecológicamente equilibrado, una calidad de vida saludable, progreso, autodeterminación de los pueblos y otros derechos difusos ${ }^{2}$. Son derechos que trascienden lo individual y lo colectivo en la medida en que los intereses individuales o privados se subordinan a intereses de la mayoría en pro del bienestar social. Tienen como característica su titularidad colectiva, que muchas veces es indefinida o indeterminable ${ }^{3}$.

La Constitución brasileña de 1988, al asegurar la protección del medio ambiente en su artículo 225 , fortalece el principio de la función ecológica de la propiedad ${ }^{4}$, imponiendo

\footnotetext{
${ }^{1}$ GUERRA FILHO, W. S., Processo Constitucional e Direitos Fundamentais, Celso Bastos Editor, São Paulo, 2003, p. 20.

${ }^{2}$ El artículo 81, parágrafo único, de la Ley núm. 8.078/90, que instituyó el Código de Defensa del Consumidor, trae de forma innovadora el concepto legal de derecho difuso, que es aplicado para todo el microsistema de derecho colectivo. Derechos difusos son aquellos cuyo interés abarca un número indeterminado de personas unidas por una situación de hecho. En suma, son aquellos derechos que pertenecen a todos y al mismo tiempo no son de nadie de forma específica.
}

${ }^{3}$ WOLFGANG SARLET, I., A eficácia dos direitos fundamentais, Livraria do Advogado, Porto Alegre, 2007, p. 53.

${ }^{4}$ Sobre el tema, es interesante destacar la postura que viene siendo mantenida en el STJ acerca de la función ecológica de la propiedad: "Nos regimes jurídicos contemporâneos, os imóveis —rurais ou urbanos - transportam finalidades múltiplas (privadas e públicas, inclusive ecológicas), o que faz com que sua utilidade econômica não se esgote em um único uso, no melhor uso e, muito menos, no mais 
obligaciones positivas y negativas al propietario en virtud del principio de la solidaridad.

De acuerdo con la tendencia mundial seguida después de la Declaración de Estocolmo, de 1972, y las directrices contenidas en el Informe Brundtland ${ }^{5}$, la Constitución Federal de 1988 , por medio de su artículo 225 , caput, y artículo $5 .^{\circ}, \S 2 .^{\circ}$, atribuyó, de forma inédita, al derecho al ambiente el estatus de derecho fundamental del individuo y de la colectividad, consagrando de esta manera la protección ambiental como uno de los objetivos o tareas fundamentales del Estado brasileño.

En 1995, el Supremo Tribunal Federal (STF) reconoció la iusfundamentalidad del derecho al medio ambiente en proceso paradigmático, como se extrae del siguiente fragmento del voto del relator, ministro Celso de Mello:

"El derecho al medio ambiente ecológicamente equilibrado — derecho de tercera generación - constituye prerrogativa jurídica de titularidad colectiva, reflejando, dentro del proceso de afirmación de los derechos humanos, la expresión significativa de un poder atribuido no al individuo identificado en su singularidad, sino, en un sentido verdaderamente más amplio, a la propia colectividad social. Mientras que los derechos de la primera generación (derechos civiles y políticos) que comprenden las libertades clásicas, negativas o formales, realzan el principio de la libertad y los derechos de segunda generación (derechos económicos, sociales y culturales), que se identifican con las libertades positivas, reales o concretas, acentúan el principio de igualdad, los derechos de tercera generación, que materializan poderes de titularidad colectiva atribuidos genéricamente a todas las formaciones sociales, consagran el principio de solidaridad y constituyen un momento importante en el proceso de desarrollo, expansión y reconocimiento de los derechos humanos, caracterizados como valores fundamentales indisponibles, por la nota de un esencial carácter inagotable" $" 67$.

lucrativo uso. A ordem constitucional-legal brasileira não garante ao proprietário e ao empresário o máximo retorno financeiro possível dos bens privados e das atividades exercidas". SUPERIOR TRIBUNAL DE JUSTIÇA. REsp 1109778 / SC. Rel. ministro Herman Benjamin, Segunda Turma, DJ 04/05/2011.

5 COMISSÃO MUNDIAL SOBRE O MEIO AMBIENTE E DESENVOLVIMENTO, Nosso futuro comum, Fundação Getúlio Vargas, Río de Janeiro, 1991, p. 46.

6 Traducción propia del original en portugués. SUPREMO TRIBUNAL FEDERAL. MS 22164/SP. Relator ministro Celso de Mello. DJ 30/10/1995.

${ }^{7}$ Diez años después, en la ADIMC 3540-1/DF, el STF reforzó esa postura, también con la relatoría del ministro Celso de Mello. SUPREMO TRIBUNAL FEDERAL. ADIMC 3540-1/DF. Relator ministro Celso de Mello. DJ 01/09/2005. 
Así, afirmar que el derecho al medio ambiente es fundamental trae innúmeras implicaciones para el ordenamiento jurídico brasileño. La referida norma es un poderoso instrumento exegético que, de acuerdo con Andreas Krell, se torna "un verdadero guía para la adecuada comprensión de los dispositivos infraconstitucionales". Destaca, además, que "su elevada posición jerárquica determina la (re)lectura de las normas de nivel ordinario y debe ser considerada a la hora de balancear los intereses en conflicto"s.

\subsection{La naturaleza axiológica del derecho fundamental al medio ambiente} ecológicamente equilibrado y su contenido esencial

Uno de los temas que más demanda investigación en el ámbito constitucional contemporáneo sobre la vertiente del neoconstitucionalismo y del pospositivismo ${ }^{9}$ es identificar la naturaleza jurídica de una norma, si es una regla o un principio. La naturaleza de la norma influencia directamente su proceso de interpretación y de aplicación, por lo que es importante el estudio en torno de la naturaleza jurídica de la norma que protege el medio ambiente.

En lo que respecta a las normas de derechos fundamentales, cabe resaltar que no existe identidad perfecta entre derechos fundamentales y principios. Sin embargo, es perceptible el carácter axiológico que las normas de derechos fundamentales poseen por el contenido esencial con respecto a los bienes jurídicos que buscan proteger ${ }^{10}$.

De acuerdo con la doctrina mayoritaria, un modelo puro de principios es inadecuado, en la medida en que la ausencia de normas-regla dificultaría establecer limitaciones a los principios que consagran derechos fundamentales, en detrimento de la seguridad

\footnotetext{
${ }^{8}$ Traducción propia del original en portugués. JOACHIM KRELL, A., Desenvolvimento sustentável às avessas nas praias de Maceió/AL: a liberação de espigões pelo Novo Código de Urbanismo e Edificações, EDUFAL, Maceió, 2008, p. 65.

${ }^{9}$ BONAVIDES, P., Curso de Direito Constitucional, Malheiros, São Paulo, 2006.

${ }^{10}$ AFONSO DA SILVA, V., Direitos fundamentais: conteúdo essencial, restrições e eficácia, Malheiros, São Paulo, 2009.
} 
jurídica y su concretización ${ }^{11}$. Robert Alexy señala que un modelo basado puramente en principios no permite una consideración seria y efectiva de la constitución escrita ${ }^{12}$.

La crítica de Alexy (así como de gran parte de la doctrina) acerca de la abstracción, la relatividad y la inseguridad jurídica inherentes a un modelo puro de principios puede ser refutada. Las corrientes que defienden que los derechos fundamentales son binormativos apuntan que es papel del intérprete decidir, en el momento de la aplicación, si el referido derecho fundamental es una regla o un principio.

La distinción entre reglas y principios no se refiere a los textos jurídicos, sino a las normas que contienen ${ }^{13}$ ¿Sobre qué criterios el intérprete decidirá acerca de la naturaleza jurídica de un derecho fundamental? Bien, dependerá de cómo quiera que el referido derecho se haga efectivo y, en consecuencia, de cómo defina la mejor forma de lidiar con una colisión (o conflicto, si son reglas). Si se trata de una colisión entre el derecho al medio ambiente y el derecho de propiedad, por ejemplo, en caso que el intérprete quiera, previamente, que prevalezca el derecho de propiedad de modo total y definitivo, dirá que se trata de una regla, excluyendo, por lo tanto, cualquier hipótesis en el derecho al medio ambiente sea efectivamente aplicado. Por otro lado, en el caso de que sea el intérprete opte por la convivencia entre ambos derechos fundamentales, los tratará como principios. En este sentido, podría decirse que las mismas críticas que pueden hacerse al modelo puramente de principios pueden realizarse a un sistema binormativo de derechos fundamentales en la medida en que dependerá del intérprete decidir cuál será la naturaleza jurídica del derecho en el momento de su aplicación. Sin embargo, al tratarse de derechos fundamentales, se percibe que no es solo su fuerte contenido axiológico que conlleva su definición en términos de principios, sino también su apertura semántica y dimensión objetiva. ${ }^{14}$

Ante esto, se defiende que los derechos fundamentales son asegurados por normasprincipio, a la luz de una teoría externa, con contenido esencial relativo. El derecho

\footnotetext{
${ }^{11}$ D’ÁVILA LOPES, A. M., Democracia hoje: para uma leitura crítica dos direitos fundamentais, UPF, Passo Fundo, 2001, p. 21.

${ }^{12}$ Vid. ALEXY, R., Teoria dos Direitos Fundamentais, traducción de Virgílio Afonso da Silva, Malheiros, São Paulo, 2008, p. 122.

${ }^{13}$ AVILA, H., Teoria dos princípios: da definição à aplicação dos princípios jurídicos, Malheiros, São Paulo, 2011, p. 44.

14 GONÇALVES PEREIRA, J. R., Interpretação constitucional e direitos fundamentais: uma contribuição ao estudos das restrições de direitos fundamentais na teoria dos principios, Renovar, Río de Janeiro, 2006, p. 94.
} 
fundamental al medio ambiente ecológicamente equilibrado, así como todos los derechos fundamentales, poseen un contenido esencial derivado de su naturaleza de principios, núcleo que representa la propia justicia, esencia del Derecho. El referido contenido no es absoluto ni inmutable. A fin de cuentas, ¿para qué sirve el Derecho? De una forma sencilla, puede afirmarse que el derecho tiene como objetivo regular las conductas humanas en pro de la pacificación social, o sea, en busca de justicia. Dignidad de la persona, contenido esencial y justicia son elementos que están intrínsecamente vinculados entre sí por caracterizar la propia esencia del Derecho. Son conceptos marco que serán concretizados por el intérprete, que considerará todas las condiciones fácticas y jurídicas del caso en particular. Al violar uno, todos los otros serán alcanzados como efecto dominó.

Tratándose del derecho fundamental al medio ambiente, se constata que su contenido esencial está constituido por una calidad de vida saludable. Se habla, incluso, de dimensión ecológica de la dignidad humana, lo que implica una matriz básica de los demás derechos fundamentales. Acerca del tema, Tiago Fensterseifer defiende lo siguiente:

“[...] el concepto jurídico de dignidad humana formulado por Sarlet como molde conceptual-normativo (abierto) es punto de partida para pensar (y reformular) el referido concepto de acuerdo con los nuevos desafíos existenciales impuestos por la degradación ambiental (pero también en vista de la evolución cultural y de los nuevos valores socioambientales legitimados en el ámbito comunitario), consagrándose su dimensión ecológica" ${ }^{\# \text {. }}$

Como objeto de un derecho fundamental, del medio ambiente pueden predicarse la irrenunciabilidad, la inalienabilidad y la imprescriptibilidad, características que, según Herman Benjamin, informan los principios estructuradores del orden público ambiental $^{16}$. Por esa razón, cuando el derecho fundamental al medio ambiente colisiona con otros derechos fundamentales, el que no prevalezca en el caso concreto no puede ser simplemente excluido del ordenamiento jurídico porque desnaturalizaría la propia razón de ser del derecho.

\footnotetext{
${ }^{15}$ Traducción propia del original en portugués. FENSTERSEIFER, T., Direitos fundamentais e proteção do meio ambiente: a dimensão ecológica da dignidade humana no marco jurídico-constitucional do Estado Socioambiental de Direito, Livraria do Advogado, Porto Alegre, 2008, p. 35.

${ }^{16}$ HERMAN BENJAMIN, A., "Constitucionalização do ambiente e ecologização da Constituição brasileira", Morato Leite, J. R. y Gomes Canotilho, J. J. (org.), Direito Constitucional Ambiental Brasileiro, Saraiva, São Paulo, 2008, p. 98.
} 


\subsection{La doble dimensión del derecho fundamental al medio ambiente}

Un punto interesante que merece ser analizado es si existe un derecho fundamental del ambiente o un derecho fundamental al medio ambiente. En otras palabras, analizar, aunque sea brevemente, las dimensiones objetiva y subjetiva de medio ambiente.

Al analizar el tema, Gomes Canotilho afirma que la discusión ya no se refiere a las positivaciones constitucionales del medio ambiente, momento prácticamente superado una vez que su constitucionalización ya fue realizada por la mayoría de los Estados. Lo que motiva ciertos cuestionamientos es cómo fue tutelado el referido derecho fundamental dado que "algunas constituciones se preocuparon más por el derecho del ambiente que por el derecho al ambiente" ${ }^{, 17}$.

Esto se debe al hecho de que el medio ambiente tiene una doble acepción: objetiva y subjetiva. La dimensión objetiva trata del ambiente como fin y tarea del Estado y de la comunidad. En la medida en que el derecho al medio ambiente aparece en la visión subjetiva, posee naturaleza de derecho subjetivo individual. Cuando se trata de la perspectiva objetiva, también llamada "objetivo-valorativa" por Ingo Sarlet, significa que existen elementos objetivos de una comunidad que deben ser guiados por el Estado. Así, se muestra como un orden objetivo de valores que irradia sobre el medio ambiente ecológicamente equilibrado ${ }^{18}$.

Gomes Canotilho resalta que la Constitución portuguesa de 1976, así como la Constitución española de 1978, disponen de un derecho fundamental al medio ambiente, o sea, lo tratan en su dimensión subjetiva y objetiva. Por otra parte, en textos más recientes, como es el caso de Alemania o Finlandia, la protección del medio ambiente se articula en términos objetivos, sin reconocimiento de derecho alguno ${ }^{19}$. Al respecto, cabe preguntar qué es lo que cambia en términos jurídico-dogmáticos. El considerar el medio ambiente tan solo en su dimensión objetiva implica sostener que las normas-tarea o normas-fin correspondientes "no garantizan posiciones jurídico-subjetivas,

\footnotetext{
17 Traducción propia del original en portugués. GOMES CANOTILHO, J. J., Estudos sobre Direitos Fundamentais, Coimbra Editora, Coimbra, 2004, p. 179.

${ }^{18}$ WOLFGANG SARLET, “A eficácia...”cit., p. 147.

${ }^{19}$ GOMES CANOTILHO, “Estudos sobre...” cit., p. 179.
} 
dirigiéndose fundamentalmente al Estado y otros poderes públicos. No obstante, constituyen normas jurídicas objetivamente vinculantes"20.

En el plano práctico, el autor lusitano destaca tres consecuencias: la primera se refiere a la existencia de auténticos deberes jurídicos dirigidos al Estado y demás poderes públicos; la segunda, a la dimensión objetiva de la "constitucionalización de bienes (o valores) jurídico-constitucionales decisivamente relevantes en la interpretación o concretización de otras reglas y principios constitucionales"; y la última, a la prohibición constitucional de retroceso ecológico-ambiental, teniendo el agravamiento de la situación ecológica global como un criterio básico de evaluación, pues solo así será posible proceder en algunos casos a la ponderación o balance de bienes ${ }^{21}$.

En lo que respecta a la acepción subjetiva del referido derecho fundamental, es importante observar que el tratamiento jurídico-constitucional del medio ambiente como bien jurídico autónomo solo será posible en caso de que así esté previsto en la Constitución, so riesgo de disolverse en la protección de otros bienes constitucionalmente relevantes. O sea, en caso de que solo exista la dimensión objetiva, explica Gomes Canotilho lo siguiente:

“[...] la consagración constitucional del ambiente como tarea de los poderes públicos puede ser suficiente para imponer responsabilidades ecológicas al Estado (y otros poderes públicos), pero no tiene operacionalidad suficiente para recortar un ámbito normativo que garantiza posiciones subjetivas individuales en lo que respecta al ambiente" 22 .

De acuerdo con Robert Alexy, el medio ambiente es objeto de un derecho fundamental, a la vez que representa un abanico paradigmático de situaciones susceptibles de normativización que tutelan derechos fundamentales. Por consiguiente, el derecho al medio ambiente puede referirse al derecho del Estado: a) de abstenerse de intervenir en el medio ambiente (derecho de defensa); b) de proteger al ciudadano contra terceros que causen daños al medio ambiente (derecho de protección); c) de permitir la participación de los ciudadanos en los procesos relativos a la toma de decisiones que afecten al medio

\footnotetext{
${ }^{20}$ Traducción propia del original en portugués. GOMES CANOTILHO, "Estudos sobre..." cit., p. 181.

${ }^{21}$ Traducción propia del original en portugués. GOMES CANOTILHO, "Estudos sobre..." cit., pp. 182ss.

${ }^{22}$ Traducción propia del original en portugués. GOMES CANOTILHO, “Estudos sobre...” cit., p. 184.
} 
ambiente (derecho al procedimiento); $\mathrm{y}$, finalmente, $\mathrm{d}$ ) de realizar medidas fácticas que busquen mejorar las condiciones ecológicas (derecho de prestaciones de hecho) ${ }^{23}$.

Al analizar el artículo 5. ${ }^{\circ}$ de la Carta Magna de Brasil se percibe que el derecho al medio ambiente no fue contemplado en esa norma, estando, en principio, fuera de su catálogo. Sin embargo, la doctrina ya es unánime al defender que el rol de los derechos y las garantías del artículo $5 .^{\circ}$ no es taxativo, en la medida en que el $\S 2 .^{\circ}$ del artículo $5 .^{\circ}$ trae una apertura de todo el ordenamiento jurídico nacional al sistema internacional de protección de los derechos humanos y de los derechos derivados del régimen y de los principios adoptados por la Constitución.

De hecho, la Carta Magna brasileña reconoce expresamente al ambiente ecológicamente equilibrado como medio para la preservación de la vida humana, lo que implica afirmar que el referido derecho fundamental tiene estatus formal (pues está previsto en el texto - art. 255, caput_-) y material (porque su contenido es imprescindible para la dignidad humana). Tiene, por consiguiente, aplicabilidad inmediata, con fundamento en el artículo $5 .^{\circ}, \S 1 .^{\circ}$, de la Constitución de 1988, por poseer la supremacía normativa conferida por el orden jurídico constitucional. Se trata de la coherencia interna de los derechos fundamentales, basados en el principio fundamental de la dignidad de la persona humana defendido por Sarlet y capaces de generar efectos jurídicos ${ }^{24}$.

Sobre la eficacia del derecho al medio ambiente, son las propias actitudes del hombre las que generan la desarmonía ambiental, lo que legitima el medio ambiente como derecho fundamental y justifica su aplicabilidad inmediata, alejando definitivamente su clasificación de norma programática.

La cuestión ambiental tiene relevancia especial en la misión de tutelar y desarrollar el principio de la dignidad humana o como desdoblamiento inmediato de la corresponsabilidad generacional. Sampaio afirma que "se puede hablar en Brasil de un derecho fundamental al medio ambiente ecológicamente equilibrado, así como se puede referir a un 'ordenamiento ambiental' que completa y condiciona el 'ordenamiento económico' y que se integra en el 'ordenamiento social',25.

\footnotetext{
${ }^{23}$ ALEXY, "Teoria dos direitos..." cit., p. 429.

${ }^{24}$ WOLFGANG SARLET, “A eficácia...” cit., pp. 78 ss.

${ }^{25}$ Traducción propia del original en portugués. LEITE SAMPAIO, J. A., "Constituição e Meio Ambiente na Perspectiva do Direito Constitucional Comparado”, Leite Sampaio, J. A., Wold, C. y Nardy, A. (org.),
} 
El derecho al medio ambiente ecológicamente equilibrado debe ser garantizado tanto a las generaciones presentes como a las futuras. Para la implementación de este derecho, existen valiosos principios e instrumentos en la legislación ambiental brasileña que pueden y deben dirigir la actuación del Estado en la tutela del medio ambiente.

1.3. La titularidad del derecho fundamental al medio ambiente: la necesidad de un abordaje ético

De acuerdo con el artículo 225 de la Constitución Federal de 1988, todos tienen derecho al medio ambiente ecológicamente equilibrado. Al respecto, es necesario plantear el siguiente interrogante: ¿quién hace parte del contenido de "todos"? Es decir, ¿quién es el titular del derecho fundamental al medio ambiente? El derecho utiliza la ética para responder esa pregunta en la medida en que la ética pauta cualquier relación humana con los demás seres vivos. Si los valores y las percepciones sociales son modificados, tarde o temprano se transforma el cuadro jurídico que rige la comunidad, como ocurrió con la esclavitud y posteriormente con los derechos de la mujer ${ }^{26}$. En ese sentido, es necesario un debate, por medio de fundamentos éticos, acerca del tratamiento dado a la naturaleza.

Ecología y ética están interconectadas por la necesidad de impacto de la segunda sobre la primera, así como por el desafío que la ecología sugiere para la reflexión ética. Por consiguiente, hay diversos enfoques éticos para cada uno de los seres o sistemas que habitan el planeta, lo que lleva a la concepción de medio ambiente adoptada en el ordenamiento jurídico de cada Estado. Existen varias corrientes, pudiendo destacarse el antropocentrismo y la ecología profunda (deep ecology $)^{27}$.

El antropocentrismo clásico defiende que el hombre está en el centro del medio ambiente, es decir, este sirve solamente para satisfacer los intereses humanos. La ética antropocéntrica tradicional puede ser fundamentada en el pensamiento kantiano, que

Principios de Direito Ambiental na Dimensão Internacional e Comparada, Del Rey, Belo Horizonte, 2003, p. 98.

${ }^{26}$ HERMAN BENJAMIN, “Constitucionalização do ambiente...” cit., pp. 49 ss.

${ }^{27}$ Herman Benjamin clasifica los textos y dispositivos normativos en tres modelos ético-jurídicos básicos: antropocentrismo puro, antropocentrismo intergeneracional y no antropocentrismo. HERMAN BENJAMIN, A., "A Natureza no Direito Brasileiro: coisa, sujeito ou nada disso", Ivo Carlin, V. (org.), Grandes Temas de Direito Administrativo: homenagem ao Professor Paulo Henrique Blasi, Millenium, Campinas, 2009, p. 52. 
defiende que el ser humano no puede ser simple "medio" (objeto) para la satisfacción de cualquier voluntad ajena, sino que siempre debe ser tomado como un "fin en sí mismo" (sujeto) en cualquier relación, sea con el Estado o con los demás individuos ${ }^{28}$. Ese abordaje implica una visión utilitarista del ambiente.

Sin embargo, el antropocentrismo tiene como desdoblamiento el economicocentrismo y el antropocentrismo alargado". La dimensión economicocéntrica "reduce el bien ambiental a valores de orden económico, lo que conlleva que cualquier consideración ambiental tenga como 'telón de fondo' el provecho económico del ser humano" ${ }^{\text {"30 }}$. Por su parte, el antropocentrismo ampliado destaca la responsabilidad del hombre con la naturaleza, siendo el guardián de la biosfera.

El antropocentrismo ampliado, a pesar de centrarse en las discusiones al respecto del ambiente en la figura del ser humano, propugna nuevas visiones del bien ambiental. Así, centra la preservación ambiental en la garantía de la dignidad del propio ser humano, rechazando una visión estrictamente económica del ambiente. El "alargamiento" de esa visión antropocéntrica reside justamente en consideraciones que imprimen ideas de autonomía del ambiente como requisito para la garantía de la supervivencia de la propia especie humana ${ }^{31}$.

De manera que es posible apreciar una evolución de un panorama menos antropocéntrico en que los valores de protección de la naturaleza reciben una especial atención, con la construcción, incluso, de una nueva ética ambiental ${ }^{32}$.

La ecología profunda, por su parte, defiende que el hombre debe integrarse en el medio ambiente, sin separar los seres humanos del medio ambiente natural. No existe nada de forma aislada y sí una gran cadena en donde todos los objetos y seres están vinculados. Así, de acuerdo con la lección de Capra, la deep ecology "reconoce el valor intrínseco

\footnotetext{
${ }^{28}$ KANT, I., Crítica da razão pura, traducción de Valerio Rohden, Martins Fontes, São Paulo, 2002, p. 229.

${ }^{29}$ MORATO LEITE, J. R., "Sociedade de risco e Estado", Morato Leite, J. R. y Gomes Canotilho, J.J. (org.), Direito Constitucional Ambiental Brasileiro, Saraiva, São Paulo, 2008, p. 137.

${ }^{30}$ Traducción propia del original en portugués. MORATO LEITE, "Sociedade de risco...” cit., p. 137.

${ }^{31}$ MORATO LEITE, "Sociedade de risco..." cit., p. 137.

${ }^{32}$ MORATO LEITE, J. R., Dano ambiental: do individual ao coletivo extrapatrimonial, Revista dos Tribunais, São Paulo, 2003, pp. 73 ss.
} 
de todos los seres vivos y concibe a los seres humanos apenas como un hilo particular en la tela de la vida" ${ }^{33}$.

La crisis ecológica, de acuerdo con Ost, no reside solo en la destrucción de los recursos ambientales, sino también en la propia relación humana con la naturaleza. Para el autor:

"Mientras no sea repensada nuestra relación con la naturaleza y mientras no seamos capaces de descubrir lo que de ella nos distingue y lo que a ella nos vincula, nuestros esfuerzos serán en vano, como lo muestra la tan relativa efectividad del derecho ambiental y la tan modesta eficacia de las políticas públicas en este dominio" 34 .

Los defensores de la ecología profunda (no antropocéntrica), sea en la visión biocéntrica o zoocéntrica (ecocéntrica), aportan fundamentos teóricos, filosóficos y éticos para la defensa del derecho de los animales y de la naturaleza. Se sustenta, por consiguiente, la posibilidad de que los animales no humanos ${ }^{35}$, así como la naturaleza, sean sujetos de derecho, al imponerse una nueva fundamentación ecológica de la dignidad humana ${ }^{36}$. Como adeptos de la visión biocéntrica se destaca un fuerte grupo de pensadores del derecho ${ }^{37}$.

Defensor de una ética ambiental centrada en los animales, Holmes Rolston destaca que son cuatro los aspectos más críticos que el ser humano afronta actualmente: paz, población, desarrollo y medio ambiente. Todos están interconectados. De acuerdo con el autor, "los deseos humanos por el desarrollo máximo impulsan el aumento de la población, aceleran la explotación del medio ambiente y alimentan las fuerzas de la guerra" ${ }^{38}$. En esa línea de razonamiento, defiende una ética ambiental por medio de una

\footnotetext{
33 Traducción propia del texto original consultado en portugués. CAPRA, F., A teia da vida: uma compreensão científica dos sistemas vivos, Cultrix, São Paulo, 1996, p. 12.

34 Traducción propia del texto original consultado en portugués. OST, F., A natureza à margem da lei: a ecologia à prova do direito, Piaget, Lisboa, 1997, p. 9.

${ }^{35}$ SINGER, P., Libertação animal, Lugano, Porto Alegre, 2004, pp. 4 ss.; REGAN, T., Defending animal rights, University of IIIinois Press, Urbana and Chicago, 2001, pp. 10 ss.; SANTANA GORDILHO, H. J., Abolicionismo Animal, Evolução, Salvador, 2008, pp. 64 ss.

${ }^{36}$ FENSTERSEIFER, "Direitos fundamentais e proteção...” cit., pp. 31 ss.

${ }^{37}$ La concepción biocéntrica del medio ambiente, de acuerdo con Abelha Rodrigues, es la única forma del ser humano para preservarse a sí mismo. ABELHA RODRIGUES, M., Elementos de Direito Ambiental: parte geral, Revista dos Tribunais, São Paulo, 2005, p. 66.

38 Traducción propia del texto original consultado en portugués. ROLSTON, H., "Ética ambiental", Bunning, N. y Tsui-James, E.P. (org.), Compêndio de Filosofia, traducción de Luiz Paulo Rouanet, Edições Loiola, São Paulo, 2007, p. 560.
} 
preocupación con valores y deberes en relación con el mundo natural. Esa ética no es solo para las personas, sino también para los animales:

"Un animal valora su vida por lo que es en sí, sin una referencia adicional, a pesar de que, es evidente, habite un ecosistema del cual depende el sustento de su vida. Los animales son capaces de valores, capaces de valorizar las cosas en su mundo, sus propias vidas intrínsecamente y sus recursos de manera instrumental. Así, puede y debe haber una ética del bienestar animal; o, como algunos prefieren decir, una ética de los derechos de los animales" ${ }^{\prime 39}$.

El principio de responsabilidades es invocado por Hans Jonas como forma de construir una nueva ética para la civilización tecnológica. Antes que un deber jurídico, se está ante un deber moral, con el objetivo de guiar no solo de las conductas humanas, sino también de la forma como se relaciona con el medio ambiente ${ }^{40}$.

De modo que, dependiendo de la perspectiva ética abordada, habrá influencia para el derecho, afectando, indudablemente, la titularidad del derecho fundamental al medio ambiente. Sobre el tema, merece especial atención la corriente geocéntrica, teniendo en cuenta los recientes eventos internacionales como los cambios constitucionales ocurridos en países de América del Sur como Bolivia y Ecuador.

Las religiones ancestrales diseñaron el universo como una gran madre. Las grandes diosas representaban el propio planeta Tierra o el principio creador de la vida, la cual inspiraba temor y reverencia. Solamente la Tierra tenía el poder de producir y nutrir la vida, sin ella la vida en el planeta se extinguiría. Es por eso por lo que el culto a la Gran Madre era la religión más difundida en las sociedades primitivas. En la América andina precolombina, la civilización inca estaba tan influida por ese simbolismo que identificó el planeta Tierra como Pachamama, que en lengua quechua significa Madre Tierra.

La nueva Constitución de Ecuador, aprobada mediante referendo popular, entró en vigor el día 20 de octubre de 2008 y supuso la abolición de la antigua Carta Magna de 1998. La actual Constitución de Ecuador, en su capítulo séptimo, de forma inédita consagra los derechos de la naturaleza o Pachamama ${ }^{41}$. Así, establece de forma original una

\footnotetext{
${ }^{39}$ Traducción propia del texto original consultado en portugués. ROLSTON, “Ética...”, cit., p. 560.

40 JONAS, H., O principio da responsabilidade: ensaio de uma ética para a civilização tecnológica, Contraponto, PUC-Rio, Río de Janeiro, 2006, pp. 39 ss.

41 “Art. 71.- La naturaleza o Pacha Mama, donde se reproduce y realiza la vida, tiene derecho a que se respete integralmente su existencia y el mantenimiento y regeneración de sus ciclos vitales, estructura, funciones y procesos evolutivos.
} 
protección jurídica ambiental ampliada que incluye la obligatoriedad del Estado en lo que respecta al control, así como instrumentos y restricciones importantes frente a la lesividad y el riesgo del bien ambiental:

1. Medidas adecuadas y transversales para el control del cambio climático, de acuerdo con el artículo 414.

2. Prohibición del cultivo de semillas transgénicas, de acuerdo con el artículo 401.

3. Prohibición de cesión del derecho de propiedad intelectual obtenida a través del conocimiento tradicional asociado a la biodiversidad nacional, artículo 402 .

4. Establecimiento de instrumentos de gestión de riesgos por el poder público para poder hacer frente a los efectos negativos de los desastres naturales o antrópicos, mediante acciones de prevención y mitigación frente al control de riesgos, además de la recuperación y el mejoramiento de las condiciones sociales, buscando minimizar las condiciones de vulnerabilidad, de acuerdo con el artículo 389.

5. Prohibición de explotación de recursos no renovables en áreas protegidas, conforme al artículo 407.

Con el mismo espíritu, la Constitución de Bolivia, aprobada después de una consulta popular realizada el 15 de enero de 2009, contiene, en su artículo 8..$^{\circ}$, la propuesta del "buen vivir", que puede ser resumida como vivir en harmonía con la naturaleza. Tal idea se remite a los principios ancestrales e indígenas de la región, de carácter integracionista, de acuerdo con el culto de la Madre Tierra ${ }^{42}$.

La vertiente ética del zoocentrismo también está ganando adeptos. De acuerdo con las corrientes clásicas, los animales, en general, se manifiestan por medio de una programación de la naturaleza, por instinto o por estímulos externos. Están siendo

Toda persona, comunidad, pueblo o nacionalidad podrá exigir a la autoridad pública el cumplimiento de los derechos de la naturaleza. Para aplicar e interpretar estos derechos se observarán los principios establecidos en la Constitución, en lo que proceda.

El Estado incentivará a las personas naturales y jurídicas, y a los colectivos, para que protejan la naturaleza, y promoverá el respeto a todos los elementos que forman un ecosistema" (las cursivas son nuestras).

${ }^{42}$ Además de ese punto constitucional, Bolivia aprobó el 7 de diciembre de 2010 la Ley de Derechos de la Madre Tierra, propuesta por cinco confederaciones nacionales indígenas y campesinas. La norma considera la Madre Tierra como un sistema vivo dinámico formado por una comunidad indivisible de todos los sistemas de vida y de los seres vivos, interrelacionados, interdependientes y complementarios, que comparten un destino común. Consagra los principios de harmonía, del bien colectivo, de garantía de regeneración, del respeto y defensa de los derechos de la Madre Tierra, de la no mercantilización y de la interculturalidad. 
desarrollados estudios en universidades norteamericanas que buscan constatar, por medio de pruebas y experimentos, si los animales no humanos tienen una racionalidad, aunque sea mínima, lo que fortalecería la construcción de un derecho animal. La racionalidad del género Homo estaría vinculada al tamaño de la estructura cerebral. Cuanto mayor el cerebro, más habilidades se desarrollan como las matemáticas o el uso del lenguaje.

Así, basándose en argumentos evolucionistas, éticos, históricos y hermenéuticos, se defiende la extensión a los grandes primates (chimpancés, gorilas, etc.) de derechos fundamentales como el derecho a la vida, a la libertad individual, a la libertad ambulatoria o a la integridad física, entre otros ${ }^{43}$. Sobre el tema, es importante destacar que llegó al STJ un caso de hábeas corpus sobre dos chimpancés, lo que aumentó la repercusión del tema en el país, a pesar de que los recurrentes solicitaron el desistimiento del recurso regimental, considerando la regularización de la situación de los animales ${ }^{44}$. Sin embargo, es posible comprobar que la discusión crece gracias al fortalecimiento de los movimientos de defensa de los animales en el país y en el mundo y a las investigaciones científicas sobre el tema.

Al adoptar el paradigma cartesiano para analizar la relación hombre-naturaleza, es posible notar que la idea de "centrismo" acaba siendo limitada y, por consiguiente, excluyente. Al considerar la perspectiva naturaleza-objeto, el elemento naturaleza es descartado, a la vez que, sobre el enfoque naturaleza-sujeto, la exclusión está en el elemento humano. Por eso es por lo que Ost afirma que las dos vertientes están equivocadas y generan la crisis del vínculo, porque "solo pueden existir vínculos entre elementos previamente reconocidos" ${ }^{, 45}$.

Para resolver el problema dialéctico entre lo natural (naturaleza-sujeto) y lo positivo (naturaleza-objeto), el autor propone una tercera categoría, la de lo justo, que da forma a

\footnotetext{
${ }^{43}$ SANTANA GORDILHO, “Abolicionismo...” cit., pp. 64 ss.

${ }^{44}$ El caso llegó a la Corte Superior cuando el propietario de los dos chimpancés, Lili y Megh, interpuso un recurso contra la decisión del TRF de la 3. ${ }^{a}$ región que establecía que los animales fueran liberados e introducidos en la naturaleza. Él alegaba que los chimpancés no sobrevivirían si eran liberados, por lo que solicitaba que continuasen bajo su responsabilidad y custodia. La Corte inició el proceso. El ministro Castro Meira manifestó que no era procedente el requerimiento de hábeas corpus en favor de los animales por considerar que este solo es aplicable a seres humanos. A continuación, el ministro Herman Benjamin solicitó una vista y el proceso fue suspendido. El proceso, sin embargo, se extinguió ya que los recurrentes solicitaron el desistimiento por la regularización de la situación de los animales. Al respecto: SUPERIOR TRIBUNAL DE JUSTIÇA. HC 96344 / SP. Relator ministro Castro Meira. DJ 23.08.2012.

${ }^{45}$ Traducción propia del texto original consultado en portugués. OST, “A natureza à...” cit., p. 35.
} 
la naturaleza-proyecto. Sobre la perspectiva de justicia, Ost defiende un derecho intergeneracional cuyos postulados fundamentales se refieren a la responsabilidad y al patrimonio. En ese sentido, este estudio se sitúa en un antropocentrismo ampliado, adoptado por la mayor parte de la doctrina y jurisprudencia brasileña, que es una concepción ética que se centra en el ser humano, pero no porque se trate de un ser superior, sino debido a su racionalidad, es decir, su capacidad de decidir y ser responsable de sus actos. La propuesta del "centrismo" aquí utilizada no puede ser vista de forma limitada y puramente dialéctica, sino como una profunda relación de complejidad.

Por ser racional, el ser humano posee una ética solidaria en relación con todas las formas de vida y es el responsable de su propia conducta, la cual influencia tanto a la actual generación como a las futuras. Además, tiene el deber de solidaridad con las otras formas de vida, pues es el responsable del equilibrio ambiental, según la idea de justicia intergeneracional invocada por Ost. Entre los argumentos éticos que apuntan en la dirección de una justicia ambiental, o sea, justicia entre diferentes generaciones, hay por lo menos dos elementos básicos, de acuerdo con Benjamin: la "conservación de la naturaleza para las generaciones futuras, buscando asegurar la perpetuación de la especie humana" y, además, la existencia de los "mismos o superiores patrones de calidad de vida existentes actualmente" ${ }^{\text {" }}$.

Así las cosas, se defiende que una ética antropocéntrica alargada e intergeneracional fundamentada en el principio de la responsabilidad es un camino posible para una nueva relación del hombre con el medio ambiente $\mathrm{y}$, por consiguiente, consigo mismo, imprescindible para la reconstrucción de una nueva forma de ver la realidad. Sin embargo, es indiscutible que la apertura que está siendo promovida por las nuevas perspectivas éticas es importante para la evolución del derecho ambiental, el cual se une a la racionalidad jurídica compleja que se construye a partir de la mutabilidad y progresividad del conocimiento científico.

\footnotetext{
46 Traducción propia del texto en portugués. HERMAN BENJAMIN, "A Natureza no Direito Brasileiro..." cit., p. 58.
} 


\section{El medio ambiente ecológicamente equilibrado como deber fundamental}

En el derecho brasileño el derecho fundamental al medio ambiente posee las dimensiones objetiva y subjetiva, lo que supone que el ordenamiento jurídico ambiental local sea extremamente avanzado, especialmente cuando la finalidad del Derecho ambiental, de acuerdo con Michel Prieur, implica una obligación de resultado que consiste en la "mejora constante del estado del ambiente"47.

El progreso del derecho ambiental está vinculado al progreso de la humanidad, uno de los fundamentos de la República Federativa de Brasil (art. 4 ${ }^{\circ}$ IX, CF). Enseña Herman Benjamin que el texto constitucional se muestra triplemente propositivo al referirse al “progreso del País" de forma genérica como objetivo de concretización nacional. Asegura, además, un "progreso planetario" al tratarse de una mejora universal que comprende a todos los seres humanos y las bases de vida en la Tierra. Finalmente, propugna el "progreso inmaterial", fortaleciendo valores intangibles, subproductos de la ética y de la responsabilidad ${ }^{48}$.

Esto se debe a la apertura del Derecho ambiental, teniendo en cuenta la imposibilidad de conceptos cristalizados desde una perspectiva posmoderna y compleja. Definir taxativamente el bien ambiental es imposible, dado que las condiciones y los factores ecológicos, sociales y humanos, vistos de forma integrada y reflexiva, están en constante transformación y evolución, lo que crea un patrimonio político-jurídico ambiental, fruto de su evolución histórico-civilizatoria, en relación con el que se formula el principio de no regresividad.

El medio ambiente ecológicamente equilibrado es deber del Estado y derecho de todos, indistintamente, en la medida en que se revela como un derecho difuso. Además, se manifiesta como un derecho intergeneracional, motivo por el cual fortalece la tesis de deber ambiental para las futuras generaciones, adoptando el principio de equidad intergeneracional. Siguiendo esa línea de razonamiento, se observa que el Estado tiene la obligación constitucional de adoptar medidas - legislativas y administrativas - de tutela ambiental que busquen hacer efectivo ese derecho fundamental ${ }^{49}$. Al incumbir al

\footnotetext{
${ }^{47}$ PRIEUR, M., Droit de l'environnement, Dalloz, París, 2011.

${ }^{48}$ HERMAN BENJAMIN, A., "Princípio da proibição de retrocesso ambiental", Comissão de Meio Ambiente, Defesa do Consumidor e Fiscalização do Senado Federal (org.), Princípio da proibição de retrocesso ambiental, Brasília, 2012, disponible en www.senado.gov.br (último acceso 1 de septiembre de 2012), p. 56.

${ }^{49}$ PÉREZ LUÑO, A. E., Los derechos fundamentales, Editorial Tecnos, Madrid, 2005, p. 214.
} 
Estado como principal (si bien no único) obligado a proteger el ambiente, el constituyente estipuló obligaciones y responsabilidades positivas y negativas que vinculan no solo a todos los entes federados en el ejercicio de sus funciones administrativas y legislativas, sino también al constituyente derivado en la medida en que el medio ambiente pertenecería implícitamente a las cláusulas pétreas.

El párrafo $1 .^{\circ}$ del artículo 225 de la Constitución prevé los deberes que tiene como titular el poder público, intitulados de especiales, mientras que en el $2 .^{\circ}$ y el $3 .^{\circ}$ pueden observarse algunos de los deberes de la comunidad. Tan solo algunos porque el rol de deberes no es taxativo, pues existen otros en la legislación infraconstitucional.

Explica Herman Benjamin que la Constitución de 1988, al utilizar la técnica de los imperativos jurídico-ambientales mínimos, asegura "tres núcleos jurídicos duros" vinculados a la protección ambiental: a) procesos ecológicos esenciales; b) diversidad e integridad genética; y c) extinción de especies, conforme a la redacción del artículo 225 , párrafo $1 .^{\circ}$, I, II y VII. En relación con los dos primeros, se verifica un "facere, un 'actuar' (= imperativo mínimo positivo), el tercero, como un 'evitar', un non facere (= imperativo mínimo negativo)" ${ }^{, 50}$.

De esta forma, "proveer el manejo ecológico de las especies y ecosistemas" (inciso I), “definir espacios territoriales especialmente protegidos, cuya supresión solo es permitida a través de ley" (inciso III), "exigir estudio previo de impacto ambiental para la instalación de obra o actividad potencialmente causadora de significativa degradación del medio ambiente" (inciso IV) y "promover la educación ambiental" (inciso IV) son deberes estatales objetivos vinculados al deber general del Estado de garantizar y promover los procesos ecológicos esenciales.

En lo que se refiere al deber amplio de protección de la diversidad y de la integridad genética, uno de los núcleos jurídicos duros mencionados por Benjamin, se constata que abarca el deber de "preservar la diversidad y la integridad del patrimonio genético del País y fiscalizar las entidades dedicadas a la investigación y manipulación de material genético" (inciso II) y de "controlar la producción, la comercialización y el empleo de técnicas, métodos y substancias que impliquen riesgos para la vida, la calidad de vida y el medio ambiente" (inciso V).

Finalmente, el deber de evitar la extinción de especies está asegurado cuando el constituyente prevé que se debe "proteger la fauna y la flora, quedando prohibidas, de

\footnotetext{
${ }^{50}$ HERMAN BENJAMIN, “Princípio da proibição...” cit., p. 66.
} 
acuerdo con la ley, las prácticas que pongan en riesgo su función ecológica, provoquen la extinción de especies o sometan a los animales a crueldad" (inciso VII).

De esta forma, los imperativos jurídico-ambientales mínimos están vinculados al principio de prohibición de retroceso ambiental, sea desde la perspectiva de que el Estado no puede disminuir el contenido normativo-ambiental alcanzado (imperativo mínimo negativo), sea desde el enfoque de que el Estado está obligado a promover mejoras constantes en la tutela ambiental debido a las incertezas científicas y a las nuevas tecnologías (imperativo mínimo positivo).

Además, cabe destacar que los imperativos jurídico-ambientales buscan proteger el mínimo existencial ecológico, es decir, el conocido mínimo existencial se extiende para incluir la calidad ambiental. Además de los derechos ya identificados por la doctrina como integrantes de ese mínimo existencial (saneamiento básico, vivienda digna, educación básica, alimentación suficiente y salud básica, entre otros), se debe incluir dentro de ese conjunto la calidad ambiental, con el objetivo de concretizar "una existencia humana digna y saludable, ajustada a los nuevos valores y derechos constitucionales de matriz ecológica" ${ }^{21}$.

Como se ve, la protección del medio ambiente no es solo un deber del Estado, es deber de todos, sin excepción, del poder público y de la colectividad, conforme a lo dispuesto en el artículo 225 de la Carta Magna. El ser humano, en su condición de ciudadano, se torna titular del derecho al ambiente equilibrado y también sujeto activo del deber fundamental de proteger el ambiente. En virtud de ello, fueron colocados a disposición de la colectividad instrumentos jurídicos para la defensa de ese derecho difuso como la acción popular o la acción civil pública, así como instrumentos de participación en la gestión ambiental por medio de la participación en consejos ambientales y en audiencias públicas.

Es interesante observar que la sociedad acaba siendo sujeto activo y pasivo del derechodeber. En otras palabras, todos tienen derecho al medio ambiente ecológicamente equilibrado y, como consecuencia, el deber de preservarlo incumbe también a todos.

El deber ambiental efectivamente prestado genera el derecho al equilibrio ambiental concretizado. Si la sociedad tomase conciencia real de la importancia de la naturaleza,

\footnotetext{
${ }^{51}$ Traducción propia del texto en portugués. FENSTERSEIFER, "Direitos fundamentais e proteção do..." cit., p. 264.
} 
reflexionando sobre el desinterés que existió por tanto tiempo, ciertamente disminuirían los impactos ecológicos negativos.

El interés y el deber de cuidado corresponden a toda la sociedad, o sea, todas las personas tienen el deber de preservar el ambiente del planeta a fin de garantizar una calidad de vida saludable para las generaciones presentes y futuras. El deber fundamental de protección del medio ambiente tiene, por lo tanto, naturaleza jurídica y moral, siendo una guía de la conducta entre humanos, del hombre consigo mismo, así como de la relación del ser humano con todas las formas de vida ${ }^{52}$.

\section{El Estado de derecho ambiental}

La racionalidad jurídica clásica, pautada en la seguridad y en conceptos delimitados, no es suficiente para lidiar con la complejidad que tiene el Derecho ambiental, lo que conlleva que la discusión ultrapase el análisis técnico y meramente dogmático, adquiriendo un carácter interdisciplinario ${ }^{53}$.

La sociedad de riesgo, surgida de la posmodernidad (o modernidad reflexiva, dependiendo del marco teórico), demanda transformaciones en el Estado y en el derecho a fin de minimizar los impactos de la crisis ambiental y controlar las dimensiones del riesgo. Estado y derecho caminan juntos, complementándose, con el objetivo de propiciar la pacificación social. El derecho es el discurso que legitima el papel del Estado. Parece que en el actual contexto de riesgo, vinculado directamente a la problemática ambiental, urgen modificaciones teóricas y funcionales en el ámbito del derecho y del Estado.

Si lidiar con el riesgo cierto y potencial, utilizando la expresión de Beck $^{54}$, ya era difícil en el anterior paradigma, más complicado es gestionar riesgos imprevisibles, en abstracto, en virtud de las incertezas científicas. De acuerdo con esa línea de pensamiento, es preciso crear una nueva gestión preventiva por medio de la utilización de instrumentos preventivos y precautorios para lidiar con toda la complejidad ambiental de la sociedad moderna.

\footnotetext{
52 JONAS, “O princípio da responsabilidade..." cit., pp. 50 ss.

${ }^{53}$ MORIN, E. y MOIGNE, J., A Inteligência da Complexidade, Peirópolis, São Paulo, 2000, pp. 209 ss.

${ }^{54}$ BECK, U., La sociedad del riesgo, traducción de Jorge Navarro, Paidós, Barcelona, 1998.
} 
A partir del momento en que se constata que el medio ambiente saludable es condición para la vida en general y que la sociedad de riesgo torna cada vez más compleja la tarea de lidiar con el daño ambiental, es imperativo un Estado preocupado con la cuestión ecológica. De una forma objetiva, el Estado de derecho ambiental puede ser comprendido como producto de nuevas reivindicaciones fundamentales del ser humano y particularizado por el énfasis que confiere a la protección del medio ambiente. Observa Capella que la construcción del Estado de derecho ambiental presupone la aplicación del principio de la solidaridad económica y social con el propósito de alcanzar un modelo de desarrollo duradero, orientado para la búsqueda de la igualdad sustancial entre los ciudadanos mediante el control jurídico del uso racional del patrimonio natural $^{55}$.

A pesar de que el Estado de derecho ambiental es, en un primer momento, una abstracción teórica, el tratamiento que la ley fundamental de un determinado país confiere al medio ambiente puede aproximar o alejar a su gobierno de los avances propuestos por el Estado de derecho ambiental, sirviendo de meta y parámetro para este.

Ante tal consideración, es oportuno destacar que la Constitución Federal de 1988 fue el primer texto constitucional brasileño en tratar deliberadamente sobre el medio ambiente, dando a la materia un tratamiento amplio y diferenciado. A partir de un capítulo específicamente dedicado al tema, el constituyente definió lo que llegaría a ser el núcleo normativo del derecho ambiental brasileño.

Entre tanto, la protección constitucional del medio ambiente es más extensa, abarcando una serie de dispositivos que, directa o indirectamente, se relacionan con valores ambientales de forma holística y sistémica. Al respecto, Benjamin ilustra que el capítulo que versa sobre el medio ambiente no es nada más que el ápice o la parte más visible de un régimen constitucional que se dedica de forma difusa a la gestión de los recursos ambientales ${ }^{56}$.

Hay principios estructurales del Estado de derecho ambiental como el principio de precaución, el principio de prevención, el principio de responsabilidad, el principio de quien contamina paga, el principio de la participación, el principio de la ciudadanía, el principio de la democracia, el principio de la información, el principio de la prohibición

\footnotetext{
${ }^{55}$ BELLVER CAPELLA, V., Ecología: de las razones a los derechos, Ecorama, Granada, 1994.

${ }^{56}$ HERMAN BENJAMIN, “Constitucionalização do ambiente...” cit.
} 
de retroceso ecológico y el principio del mínimo existencial ecológico. Aquí se verifica que el rol de los principios que estructuran el derecho ambiental no es taxativo, puesto que la sociedad está en constante transformación, no pudiendo ser petrificada. Además, a pesar de existir consenso en la doctrina en relación con los principios clásicos, hay autores que siempre están proponiendo nuevos principios y perspectivas en la base del derecho ambiental, por lo que es importante tener presente la incesante y progresiva apertura del derecho ambiental.

Sin embargo, al analizar todos esos principios se percibe que la solidaridad acaba incluida, de forma transversal o de forma directa, en todos los demás. Es por ello por lo que el principio de la solidaridad es el fundamento teórico-jurídico del Estado de derecho ambiental, es decir, uno de los principios básicos del nuevo paradigma estatal, si bien no excluye, no obstante, a los demás.

Siguiendo esa línea de razonamiento, cabe verificar si la Carta Magna brasileña tiene la capacidad de adoptar el nuevo modelo de Estado, puesto que "la construcción del Estado de Derecho Ambiental pasa, necesariamente, por las disposiciones constitucionales, pues son ellas las que exprimen los valores y los postulados básicos de la comunidad en las sociedades de estructura compleja, en las cuales la legalidad representa racionalidad y objetividad"57.

La Constitución Federal de 1988 establece el principio de la solidaridad como objetivo de la República en su artículo 3. ${ }^{\circ}$, I, al prever la "construcción de una sociedad libre, justa y solidaria”. En el inciso IV del mismo artículo se contiene otro objetivo que corrobora la preocupación del constituyente originario por la solidaridad, al establecerse la "erradicación de la pobreza y de la marginalización social y la reducción de las desigualdades sociales y regionales". Como se ve, los dispositivos establecen un nuevo marco normativo-constitucional al consolidar la solidaridad como principio de la Carta Magna $^{58}$.

\footnotetext{
${ }^{57}$ Traducción propia del texto en portugués. MORATO LEITE, J. R. y CAVALCANTI FERREIRA, M. L. P., "As novas funções do Direito Administrativo em face do Estado de Direito Ambiental", Ivo Carlin, V. (org.), Grandes Temas de Direito Administrativo: homenagem ao Professor Paulo Henrique Blasi, Millenium, Campinas, 2009, p. 439.

${ }^{58}$ Además, es interesante mencionar que el principio de solidaridad también está previsto en el preámbulo de la Constitución Federal de 1988 al afirmar los derechos sociales e individuales, la libertad, la seguridad, el bienestar, el desarrollo, la igualdad y la justicia como valores supremos de una sociedad fraterna. A pesar de que el preámbulo carezca de juridicidad, se trata de una carta de intenciones del constituyente que no deja de ser una norma moral que manifiesta los ideales y valores de la sociedad brasileña.
} 
Además, en el texto constitucional, el artículo 225, núcleo del ambientalismo constitucional, cuida de la solidaridad al imponer al poder público y a la colectividad el deber de proteger el medio ambiente para las presentes y futuras generaciones. No hay duda de que el deber fundamental está directamente relacionado con el principio de solidaridad y las responsabilidades en la equidad generacional. A todo ello cabe sumar que el citado principio está plasmado en tratados internacionales de derechos humanos en materia ambiental ratificados por el Estado brasileño en virtud de la cláusula de apertura del párrafo $2 .^{\circ}$ del artículo $5^{\circ}$ de la Constitución Federal ${ }^{59}$.

Considerando la teoría del riesgo, el principio de la solidaridad aparece como uno de los grandes desafíos de los juristas en la medida en que demanda interrelación entre las diversas generaciones, lo que torna la temática compleja, ya que no se sabe lo que está por venir. Herman Benjamin señala que solo cabe hacer algunas conjeturas sobre "a) quién habitará el planeta en un futuro, más allá de los días de hoy; b) las consecuencias remotas que nuestras acciones actuales provocarán en esos habitantes inciertos; y c) las preferencias de tales generaciones"

La falta de conciencia local y global en lo que respecta a las consecuencias de los impactos negativos en el medio ambiente es una de las causas más graves de la problemática ambiental. Incluso porque de nada sirve un Estado de derecho ambiental si luego al lado hay un país con total desinterés por las cuestiones ecológicas. Ni es necesario que esté cerca, dado que no hay aduanas en la atmósfera que fiscalicen la entrada y la salida de la contaminación de un país. No existe un daño ambiental que quede limitado al lugar de su realización, reforzando la necesidad de la solidaridad no solo como principio fundante del Estado ambiental, sino también como un principio universal entre los pueblos.

De antemano, ya se afirma que no se trata de una ruptura total con el Estado democrático de derecho, modelo adoptado por el constituyente originario brasileño de 1988, en los términos del artículo 1. ${ }^{\circ}$. Se trata de incluir un nuevo principio fundante que, al vincularse con los ya existentes en el ordenamiento de forma equilibrada y holística, proporcione una protección más efectiva de la tutela ambiental. Así, el

\footnotetext{
59 “Art. $5^{\circ}$. [...] $\S 2^{\circ}$ - Los derechos y garantías expresados en esta Constitución no excluyen otros derivados del régimen y de los principios por ella adoptados, o de los tratados internacionales en que la República Federativa de Brasil sea parte”. Traducción propia del texto en portugués.

${ }^{60}$ Traducción propia del texto en portugués. HERMAN BENJAMIN, "A Natureza no Direito Brasileiro..." cit., p. 59.
} 
principio de la solidaridad actuará de forma conjunta con el principio de la legitimidad ("Estado democrático") y con el principio de la juridicidad ("Estado de derecho"), además de con otros que incorporan valores elegidos por el constituyente.

No es una cuestión formal, un registro del surgimiento de un nuevo Estado. De hecho, no es tan importante para la ciencia jurídica los nombres atribuidos a las instituciones como su naturaleza jurídica. Es evidente que el nombre que se da a un Estado no transforma la realidad de la noche al día. Seguro que no. Lo que se pretende con la defensa de un Estado de derecho ambiental es el fortalecimiento de una nueva perspectiva, de una conciencia ecológica, de diferentes funciones, instrumentos, metas y tareas que puedan (y deban) ser utilizados por el poder público y por la colectividad de forma integrada, preventiva, precautoria y solidaria. Como se ve, no es un discurso romántico o utópico, sino un paradigma posible de ser implementado en el actual contexto de la posmodernidad y de la complejidad. Sin embargo, no se niega la dificultad de aplicarlo, con elementos integrantes sólidos y adecuados, por parte de estados modernos en la concretización de un nuevo principio fundamental de solidaridad y del valor de la sostenibilidad.

\section{Elementos de una hermenéutica jurídica ambiental}

De nada sirve toda la construcción teórica en torno del Estado de Derecho ambiental si no existen mecanismos concretos para implementarlo. Al adoptar el paradigma ecológico es necesario un nuevo modo de ver el ordenamiento jurídico, con una precomprensión diferenciada del intérprete, en la medida en que la hermenéutica filosófica muestra que el sentido de la norma jurídica es inagotable ${ }^{61}$.

Las normas deben ser interpretadas con el fin de concretizar el Estado de derecho ambiental. Por más que la Constitución permanezca en muchos puntos inalterada, e incluso las normas infraconstitucionales, el intérprete debe percibir el movimiento dialéctico del derecho, formado por razonamientos jurídicos no solo deductivos, sino también inductivos, lo que justifica la emergencia de una hermenéutica jurídica ambiental $^{62}$.

\footnotetext{
${ }^{61}$ BEZERRA FALCÃO, R., Hermenêutica, Malheiros, São Paulo, 2004.

${ }^{62}$ NEIVA BELCHIOR, G. P., Hermenêutica Jurídica Ambiental, Saraiva, São Paulo, 2011.
} 
La particularidad de esta hermenéutica ambiental se fortalece, además, por el hecho de que el ordenamiento jurídico ambiental está dotado de conceptos vagos, confusos, amplios e indeterminados, además de por la intensa discrecionalidad administrativa que se concede al Ejecutivo. El propio concepto de bien ambiental es jurídicamente indeterminado, puesto que sus condiciones, factores y elementos están en constante transformación. Es un concepto marco que deberá ser analizado por el intérprete en el caso concreto, de acuerdo con los conocimientos científicos existentes en el momento de su aplicación.

Además, cabe destacar que, ante el carácter principiológico de los derechos fundamentales, es inevitable la constante colisión entre estos, como ocurre entre el derecho al medio ambiente y el derecho a la propiedad, por ejemplo, lo que lleva a la necesidad de técnicas interpretativas adecuadas.

El neoconstitucionalismo demanda una construcción teórica que realice una debida adaptación de las instituciones jurídicas a los patrones definidos por la Constitución al fijar nuevos cánones de interpretación para las normas infraconstitucionales. Así, urge una nueva perspectiva hermenéutica del ordenamiento jurídico que tenga como nuevo valor la sostenibilidad, invadiendo la esfera pública y privada en razón de la ecologización.

Los referidos métodos pueden ser aplicados por todos los que lidian con el Derecho ambiental: por el legislador al elaborar las normas infraconstitucionales, en obediencia a la Constitución; por el Ejecutivo en el momento de la elaboración y de la ejecución de políticas públicas, especialmente en el caso de la licencia ambiental en virtud de la discrecionalidad administrativa; y en el caso de la fiscalía.

Finalmente, la hermenéutica ambiental es indicada para los magistrados que tratan cada vez más con demandas ambientales, considerando, además, la tendencia hacia juzgados especializados en el Poder Judicial brasileño. En verdad, la tutela judicial acaba siendo la última salida, como si el magistrado fuese el salvador del planeta y, por qué no decirlo, de todos nosotros. Dado que el juez es un ser humano, forma parte de la sociedad, él también tiene la obligación no solo de buscar la justicia en el caso concreto, 
sino también de promover la tutela ambiental en la medida en que se trata de un deber fundamental ${ }^{63}$.

Siguiendo esa línea de pensamiento, la hermenéutica jurídica ambiental es propuesta por medio de principios de interpretación que objetivan la búsqueda de soluciones justas y constitucionalmente adecuadas para la interpretación de normas ambientales, influenciados por una nueva precomprensión ambiental.

Así, se utilizan los principios fundantes (principio de la legitimidad, principio de la juridicidad y principio de la solidaridad) y los principios estructurantes del Estado de derecho ambiental ${ }^{64}$.

Además, cabe destacar el principio de interpretación constitucional, el principio de razonabilidad, el principio de ponderación y el principio de proporcionalidad, los dos últimos adecuados para tratar sobre la colisión entre derechos fundamentales ${ }^{65}$. Todos los principios acaban estando interconectados, uno dando apoyo al otro para fundamentar las tomas de decisión del intérprete.

Por otro lado, no es posible quedar limitado a los textos legales, como sugería el positivismo jurídico, ni tampoco obviarlos, como defienden algunas vertientes iusnaturalistas y del Derecho libre. El intérprete constitucional ambiental debe analizar la evolución social, propia de la dialéctica del Derecho, llenando las molduras deónticas previstas en la Constitución de acuerdo con el contexto social, realidad que se traduce en una sociedad de riesgo y posmoderna.

\footnotetext{
${ }^{63}$ Acerca del papel del juez en la protección del medio ambiente, cabe destacar los votos relatados por Herman Benjamin: "O Judiciário não desenha, constrói ou administra cidades, o que não quer dizer que nada possa fazer em seu favor. Nenhum juiz, por maior que seja seu interesse, conhecimento ou habilidade nas artes do planejamento urbano, da arquitetura e do paisagismo, reservará para si algo além do que o simples papel de engenheiro do discurso jurídico. E, sabemos, cidades não se erguem, nem evoluem, à custa de palavras. Mas palavras ditas por juízes podem, sim, estimular a destruição ou legitimar a conservação, referendar a especulação ou garantir a qualidade urbanístico-ambiental, consolidar erros do passado, repeti-los no presente, ou viabilizar um futuro sustentável". SUPERIOR TRIBUNAL DE JUSTIÇA. REsp 302906 / SP. Rel. Ministro Herman Benjamin, Segunda Turma, DJ 05/04/2011.
}

"No Brasil, ao contrário de outros países, o juiz não cria obrigações de proteção do meio ambiente. Elas jorram da lei, após terem passado pelo crivo do Poder Legislativo. Daí não precisarmos de juízes ativistas, pois o ativismo é da lei e do texto constitucional". SUPERIOR TRIBUNAL DE JUSTIÇA. REsp 650728/SC. Ministro Herman Benjamin, Segunda Turma, DJ 23/11/2007.

${ }^{64}$ NEIVA BELCHIOR, "Hermenêutica Jurídica..." cit., p. 200.

${ }^{65}$ HESSE, K., A força normativa da Constituição, traducción de Gilmar Ferreira Mendes, Sergio Antonio Fabris Editor, Porto Alegre, 2001. 
Además, la hermenéutica jurídica ambiental se muestra relevante, en la colisión de derechos fundamentales que comprenden el derecho al medio ambiente, en virtud de que los referidos derechos poseen la naturaleza jurídica de los principios, lo que hace con que entren fácilmente en ruta de colisión entre sí ${ }^{66}$. Además, los criterios tradicionales de antinomias no son suficientes para tratar la colisión de derechos fundamentales, lo que implica la necesidad de una técnica específica de solución.

El derecho fundamental al medio ambiente posee un contenido esencial derivado de su naturaleza principiológica. Ese contenido no es absoluto ni inmutable. Es maleable, siendo definido por el intérprete en el momento de su aplicación mediante los principios de ponderación y de proporcionalidad. Los principios de precaución ${ }^{67}$ (incluso en su manifestación por medio del principio in dubio pro natura $)^{68}$, de mínimo existencial ecológico y de prohibición de retroceso ecológico tendrán también un papel imprescindible en la delimitación del núcleo esencial del derecho al medio ambiente.

Por ello, cuando ocurre la colisión entre el derecho fundamental al medio ambiente y otros derechos fundamentales, aquel que no prevalezca en el caso concreto no puede ser simplemente excluido del ordenamiento jurídico porque ello desnaturalizaría la propia esencia del derecho.

Ante una colisión del derecho al medio ambiente con otro derecho fundamental, en un primer momento el intérprete deberá sopesar y utilizar el principio de ponderación para buscar armonizar los bienes, valores e intereses implicados en el caso concreto por medio de mandamientos de optimización, conforme a lo sugerido por Robert Alexy ${ }^{69}$.

La ponderación se realiza en un momento anterior a la aplicación del principio de proporcionalidad, al buscar armonizar los intereses, los valores y los bienes implicados en la colisión. En esta fase, los principios van tomando forma, concretizándose de

\footnotetext{
${ }^{66}$ AFONSO DA SILVA, "Direitos fundamentais: conteúdo essencial..." cit.

67 “[...] 4. As normas ambientais devem atender aos fins sociais a que se destinam, ou seja, necessária a interpretação e a integração de acordo com o princípio hermenêutico in dubio pro natura". SUPERIOR TRIBUNAL DE JUSTIÇA. REsp. 1.367.923-RJ. Rel. Ministro Humberto Martins, Segunda Turma, DJ 06/09/2013.

68 “[...] No contexto do Direito Ambiental, o adágio in dubio pro reo é transmudado, no rastro do princípio da precaução, carregando consigo uma forte presunção em favor da proteção da saúde humana e da biota". SUPERIOR TRIBUNAL DE JUSTIÇA. REsp 883.656/RS. Rel. Min. Herman Benjamin, Segunda Turma, DJ 28/02/2012.
}

${ }^{69}$ ALEXY, “Teoria dos direitos..." cit. 
acuerdo con las peculiaridades de los hechos ${ }^{70}$. Después de dar un peso específico a los intereses considerados relevantes, se concluye la fase de armonización y se pasa a utilizar el principio de proporcionalidad para la aplicación proporcional de los medios más adecuados, necesarios y proporcionales en sentido estricto para la solución.

La referida técnica viene experimentando críticas por parte de la doctrina por entender que esta carece de racionalidad y que, por lo tanto, da margen a la subjetividad y a la arbitrariedad del juez. Sin embargo, esta ponderación está sometida a un control racional, a pesar de ser inevitable cierto margen de subjetividad del intérprete.

De cualquier manera, queda claro que los principios no tienen por qué ofrecer respuestas únicas y exclusivas, puesto que, de acuerdo con los fundamentos filosóficos de la hermenéutica, el sentido de la norma objeto de la interpretación es inagotable ${ }^{71}$. A pesar de que el jurista utilice todos los principios interpretativos, aun así habrá margen para la subjetividad y la arbitrariedad.

El STJ ha utilizado los principios del derecho ambiental para la interpretación de las normas ambientales, lo que fortalece una hermenéutica jurídica ambiental. Es lo que ocurre con la imprescriptibilidad del daño ambiental ${ }^{72}$, la inversión de la carga de la prueba $^{73}$, el daño ambiental moral colectivo ${ }^{74}$ y la inexistencia del derecho adquirido de

70 SILVA CRISTÓVAM, J. S., Colisões entre Princípios Constitucionais: razoabilidade, proporcionalidade e argumentação jurídica, Juruá, Curitiba, 2006.

${ }^{71}$ HEIDEGGER, M., Ser e tempo, traducción de Márcia de Sá Cavalcante, parte I, Vozes, Petrópolis, 1993; GADAMER, H. G., Verdade e Método II, traducción de Enio Paulo Giachini, Vozes, Petrópolis, 2002.

72 "Entretanto, o direito ao pedido de reparação de danos ambientais, dentro da logicidade hermenêutica, também está protegido pelo manto da imprescritibilidade, por se tratar de direito inerente à vida, fundamental e essencial à afirmação dos povos, independentemente de estar expresso ou não em texto legal. [...] No conflito entre estabelecer um prazo prescricional em favor do causador do dano ambiental, a fim de lhe atribuir segurança jurídica e estabilidade, com natureza eminentemente privada, e tutelar de forma mais benéfica bem jurídico coletivo, indisponível, fundamental, que antecede todos os demais direitos - pois sem ele não há vida, nem saúde, nem trabalho, nem lazer -, este último prevalece, por óbvio, concluindo pela imprescritibilidade do direito à reparação do dano ambiental”. SUPERIOR TRIBUNAL DE JUSTIÇA. REsp 1.120.117 / AC. Rel. Min. Eliana Calmon, Segunda Turma, julgado em 10/11/2009, DJ 19/11/2009.

73 La ponente utiliza claramente los princípios del Derecho ambiental relatora como instrumento hermenêutico al exponer lo siguiente: "[...] a análise sobre o ônus da prova, em ação coletiva por dano ambiental, deve ser dirimida pela interpretação das leis aplicáveis ao mencionado instrumento processual à luz dos princípios norteadores do Direito Ambiental. Isso porque, em regra, a inversão do ônus probatórios deve assentar-se exclusivamente em disposição expressa de lei. Mas, no presente caso, essa inversão encontra fundamento também em princípios transversais ao ordenamento jurídico, quais sejam, os princípios ambientais". SUPERIOR TRIBUNAL DE JUSTIÇA. REsp 972.902 / RS. Rel. Min. Eliana Calmon, Segunda Turma, DJ 20/11/2009.

74 “ [...] c.) dano moral coletivo. Também deve ser reembolsado ao patrimônio à coletividade o proveito econômico do agente com sua atividade ou empreendimento degradador, a mais-valia ecológica ilícita 
$\operatorname{contaminar}^{75}$, a partir de la justificación de los principios de la precaución y del in dubio pro natura.

A pesar de todas las dificultades inherentes a las cuestiones existenciales y complejas del fenómeno hermenéutico, el intérprete debe fundamentar sus decisiones sobre la base de argumentos que puedan ser racionalmente justificados de acuerdo con los preceptos del nuevo orden constitucional ecológico, principalmente cuando el postpositivismo apunta que los principios no necesitan ser recogidos expresamente para tener valor normativo.

Una hermenéutica jurídica específica para lidiar con la juridicidad ambiental, por lo tanto, objetiva, debe orientar y guiar al intérprete con el propósito de captar sentidos del orden jurídico ambiental que sean convenientes con los dictámenes y postulados del Estado de derecho ambiental.

\section{CONCLUSIÓN}

Antes de la supremacía formal de la Constitución, las normas constitucionales ocupan necesariamente la precomprensión de todo intérprete de la ley, en el marco de un sistema jurídico. En este contexto, al ser el Estado el principal ente (aunque no único) obligado a proteger el ambiente (art. 225, CF), el constituyente estipuló obligaciones y responsabilidades positivas y negativas, de forma que el equilibrio del medio ambiente está protegido. No hay duda de que la matriz constitucional del artículo 225 influye en el proceso de interpretación de las normas ambientales desde una perspectiva sistémica, compleja y reflexiva.

que auferiu (p. ex., madeira ou minério retirados irregularmente de área degrada ou benefício com seu uso espúrio para fins agrossilvopastoril, turístico, comercial)". SUPERIOR TRIBUNAL DE JUSTIÇA. REsp 1.198.727 / MG. Rel. Min. Herman Benjamin, Segunda Turma, DJ 09/05/2013.

“[...] 2. A Segunda Turma recentemente pronunciou-se no sentido de que, ainda que de forma reflexa, a degradação ao meio ambiente dá ensejo ao dano moral coletivo. 3. Haveria contra sensu jurídico na admissão de ressarcimento por lesão a dano moral individual sem que se pudesse dar à coletividade o mesmo tratamento, afinal, se a honra de cada um dos indivíduos deste mesmo grupo é afetada, os danos são passíveis de indenização". SUPERIOR TRIBUNAL DE JUSTIÇA. REsp. 1.367.923-RJ. Rel. Humberto Martins, Segunda Turma, DJ 06/09/2013.

75 “....] Esta Corte é pacífica no sentido de que não há direito adquirido a poluir ou degradar o meio ambiente. De fato, 'décadas de uso ilícito da propriedade rural não dão salvo-conduto ao proprietário ou posseiro para a continuidade de atos proibidos ou tornam legais práticas vedadas pelo legislador, sobretudo no âmbito de direitos indisponíveis, que a todos aproveita, inclusive às gerações futuras, como é o caso da proteção do meio ambiente"”. SUPERIOR TRIBUNAL DE JUSTIÇA. REsp 1.222.723/SC. Rel. Ministro Mauro Campbell, Segunda Turma, DJ 17/11/2011. 
Es importante no perder de vista que la epistemología ambiental es mucho más amplia que el derecho ambiental en sí y que el ejecutor de la ley debe estar abierto al diálogo interdisciplinario y transdisciplinario.

La Constitución, así como cualquier ley ambiental, deben ser leídas bajo la luz de la crisis ambiental, la posmodernidad y la sociedad del riesgo en la medida en que los cambios normativos constitucionales contribuyen a la adecuación de la legislación a la realidad y, por lo tanto, a la progresividad del derecho ambiental. Ante la supremacía formal y material de la Constitución, las normas constitucionales ocupan, necesariamente, la preconcepción interpretativa del operador del derecho, fenómeno que puede ser caracterizado como un influjo que se proyecta en todo el ordenamiento jurídico.

En este contexto, cuando el artículo 225 de la Constitución Federal de 1988 ha establecido que el derecho a un medio ambiente ecológicamente equilibrado es un derecho y un deber de carácter fundamental, el constituyente ha asegurado al poder público, a la sociedad y al ciudadano brasileño varias obligaciones, tanto de carácter positivo (de hacer) como negativo (de no hacer), con la intención de que el medio ambiente pudiera estar protegido.

No cabe duda de que la matriz constitucional del artículo 225 influye de forma contundente en la interpretación de la normativa ambiental, poniendo las bases para una interpretación a partir de una perspectiva sistémica, reflexiva y compleja.

En este sentido, es importante no perder de vista que la epistemología ambiental es anterior y mucho más amplia que la propia disciplina del Derecho ambiental, lo que conlleva que el operador del Derecho esté abierto al diálogo interdisciplinario y transdisciplinario.

La Constitución, así como todo el ordenamiento jurídico ambiental, deben ser leídos e interpretados bajo la luz y a través de la lente de los conceptos operacionales de la crisis ambiental, la posmodernidad y la sociedad de riesgo en la medida en que los cambios normativos y constitucionales contribuyen a la adecuación del derecho a la realidad y, en consecuencia, al desarrollo de la disciplina del derecho ambiental.

\section{BIBLIOGRAFÍA}


ABELHA RODRIGUES, M., Elementos de Direito Ambiental: parte geral, Revista dos Tribunais, São Paulo, 2005.

AFONSO DA SILVA, V., Direitos fundamentais: conteúdo essencial, restrições e eficácia, Malheiros, São Paulo, 2009.

ALEXY, R., Teoria dos Direitos Fundamentais, traducción de Virgílio Afonso da Silva, Malheiros, São Paulo, 2008.

AVILA, H., Teoria dos princípios: da definição à aplicação dos princípios jurídicos, Malheiros, São Paulo, 2011.

BECK, U., La sociedade del riesgo, traducción de Jorge Navarro, Paidós, Barcelona, 1998.

BELLVER CAPELLA, V., Ecologia: de las razones a los derechos, Ecorama, Granada, 1994.

BEZERRA FALCÃO, R., Hermenêutica, Malheiros, São Paulo, 2004.

BONAVIDES, P., Curso de Direito Constitucional, Malheiros, São Paulo, 2006.

CAPRA, F., A teia da vida: uma compreensão cientifica dos sistemas vivos, Cultrix, São Paulo, 1996, p. 12.

COMISSÃO MUNDIAL SOBRE O MEIO AMBIENTE E DESENVOLVIMENTO, Nosso futuro comum, Fundação Getúlio Vargas, Río de Janeiro, 1991.

D’ÁVILA LOPES, A. M., Democracia hoje: para uma leitura crítica dos direitos fundamentais, UPF, Passo Fundo, 2001.

FENSTERSEIFER, T., Direitos fundamentais e proteção do meio ambiente: a dimensão ecológica da dignidade humana no marco jurídico-constitucional do Estado Socioambiental de Direito, Livraria do Advogado, Porto Alegre, 2008.

GADAMER, H. G., Verdade e Método II, traducción de Enio Paulo Giachini, Vozes, Petrópolis, 2002.

GONÇALVES PEREIRA, J. R., Interpretação constitucional e direitos fundamentais: uma contribuição ao estudos das restrições de direitos fundamentais na teoria dos principios, Renovar, Río de Janeiro, 2006.

GUERRA FILHO, W. S., Processo Constitucional e Direitos Fundamentais, Celso Bastos Editor, São Paulo, 2003. 
HEIDEGGER, M., Ser e tempo, traducción de Márcia de Sá Cavalcante, parte I, Vozes, Petrópolis, 1993.

HERMAN BENJAMIN, A., "Constitucionalização do ambiente e ecologização da Constituição brasileira", Morato Leite, J. R. y Gomes Canotilho, J. J. (org.), Direito Constitucional Ambiental Brasileiro, Saraiva, São Paulo, 2008.

- “A Natureza no Direito Brasileiro: coisa, sujeito ou nada disso", Ivo Carlin, V. (org.), Grandes Temas de Direito Administrativo: homenagem ao Professor Paulo Henrique Blasi, Millenium, Campinas, 2009.

- "Princípio da proibição de retrocesso ambiental", Comissão de Meio Ambiente, Defesa do Consumidor e Fiscalização do Senado Federal (org.), Princípio da proibição de retrocesso ambiental, Brasília, 2012 (disponible en: www.senado.gov.br, acceso 1 de septiembre de 2012).

HESSE, K., A força normativa da Constituição, traducción de Gilmar Ferreira Mendes, Sergio Antonio Fabris Editor, Porto Alegre, 2001.

JOACHIM KRELL, A., Desenvolvimento sustentável às avessas nas praias de Maceió/AL: a liberação de espigões pelo Novo Código de Urbanismo e Edificações, EDUFAL, Maceió, 2008.

JONAS, H., O princípio da responsabilidade: ensaio de uma ética para a civilização tecnológica, Contraponto, PUC-Rio, Río de Janeiro, 2006.

KANT, I., Crítica da razão pura, traducción de Valerio Rohden, Martins Fontes, São Paulo, 2002.

LEITE SAMPAIO, J. A., "Constituição e Meio Ambiente na Perspectiva do Direito Constitucional Comparado", Leite Sampaio, J. A., Wold, C. y Nardy, A. (org.), Princípios de Direito Ambiental na Dimensão Internacional e Comparada, Del Rey, Belo Horizonte, 2003.

MORATO LEITE, J. R., "Sociedade de risco e Estado", Morato Leite, J. R. y Gomes Canotilho, J.J. (org.), Direito Constitucional Ambiental Brasileiro, Saraiva, São Paulo, 2008.

- Dano ambiental: do individual ao coletivo extrapatrimonial, Revista dos Tribunais, São Paulo, 2003. 
MORATO LEITE, J. R. y CAVALCANTI FERREIRA, M. L. P., “As novas funções do Direito Administrativo em face do Estado de Direito Ambiental", Ivo Carlin, V. (org.), Grandes Temas de Direito Administrativo: homenagem ao Professor Paulo Henrique Blasi, Millenium, Campinas, 2009.

MORIN, E. y MOIGNE, J., A Inteligência da Complexidade, Peirópolis, São Paulo, 2000 .

NEIVA BELCHIOR, G. P., Hermenêutica Jurídica Ambiental, Saraiva, São Paulo, 2011.

PÉREZ LUÑO, A. E., Los derechos fundamentales, Editorial Tecnos, Madrid, 2005.

PRIEUR, M., Droit de l'environnement, Dalloz, París, 2011.

OST, F., A natureza à margem da lei: a ecologia à prova do direito, Piaget, Lisboa, 1997.

REGAN, T., Defending animal rights, University of IIIinois Press, Urbana and Chicago, 2001 .

ROLSTON, H., “Ética ambiental”, Bunning, N. y Tsui-James, E.P. (org.), Compêndio de Filosofia, traducción de Luiz Paulo Rouanet, Edições Loiola, São Paulo, 2007.

SANTANA GORDILHO, H. J., Abolicionismo Animal, Evolução, Salvador, 2008.

SILVA CRISTÓVAM, J. S., Colisões entre Princípios Constitucionais: razoabilidade, proporcionalidade e argumentação jurídica, Juruá, Curitiba, 2006.

SINGER, P., Libertação animal, Lugano, Porto Alegre, 2004.

WOLFGANG SARLET, I., A eficácia dos direitos fundamentais, Livraria do Advogado, Porto Alegre, 2007. 